\section{P46 ECHOCARDIOGRAPHIC EVALUATION OF CARDIAC FINDINGS IN INFANTS OF MOTHERS WITH GESTATIONAL DIABETES MELLITUS}

${ }^{1}$ Erkan Erfidan*, ${ }^{2}$ Helen Bornaun, ${ }^{1}$ Esin Yıldız Aldemir, ${ }^{2}$ Kazım Öztarhan, ${ }^{3}$ Ali Ayçicek. ${ }^{1}$ University of Health Sciences, Kanuni Sultan Suleyman Training and Research Hospital Department of Pediatrics, Istanbul, Turkey; ${ }^{2}$ University of Health Sciences, Kanuni Sultan Suleyman Training and Research Hospital - Department of Pediatric Cardiology, Istanbul, Turkey; ${ }^{3}$ University of Health Sciences, Kanuni Sultan Suleyman Training and Research Hospital - Department of Pediatric Hematology, Istanbul, Turkey

10.1136/archdischild-2019-epa.401

Aim Echocardiographic evaluation of cardiac findings in infants of mothers with gestational diabetes mellitus (GDM). Materials and Methods In this study, echocardiographic evaluation of the 70 infants born to mothers with GDM and 70 control group was conducted retrospectively in the first 24 hours of their lives.

Results Infants born to mothers with GDM and control group respectively, interventricular septum (IVS) end-diastolic thickness was found $6,1 \pm 1,0 \mathrm{~mm} ; 4,6 \pm 0,6 \mathrm{~mm}(P<0,001)$; end-systolic thickness was found $7,4 \pm 1,7 \mathrm{~mm} ; 6,7 \pm 1,1$ $\mathrm{mm} \quad(P=0,006)$; right ventricular isovolumetric contraction time (IVCT) was found 28,6 $\pm 4,8 \mathrm{msn} ; 27,1 \pm 4,4 \mathrm{msn}(P$ $=0,048$ )and ejection time $(\mathrm{ET})$ was found $211,8 \pm 21,1 \mathrm{msn}$; $219,4 \pm 17,1 \mathrm{msn}(P=0,021)$, myocardial performance index $(\mathrm{MPI})$ was found $0,37 \pm 0,08 ; 0,31 \pm 0,05 \quad(P<$ $0,001)$; the ratio of early and late diastolic flow peak flow velocity values in tissue doppler imaging (TDI E/A) was found $77 \pm 0,13 ; 0,81 \pm 0,11(P=0,032)$; left ventricular isovolumetric relaxation time (IVRT) was found 41,9 \pm 4,6 msn; $39,5 \pm 5,6 \mathrm{msn}(P=0,007)$, and MPI was found $0,45 \pm$ 0,$09 ; 0,39 \pm 0,06(P<0,001)$.

Conclusion The infants born to mothers with GDM in the first 24 hours of life, IVS was detected thicker, TDI E/A was detected lower, ET was detected longer in the right ventricle, right ventricular IVCT and left ventricular IVRT value were detected higher, MPI was detected higher in both ventricles.

\section{P47 EVALUATION OF THE USE OF PULSE OXIMETRY AND COMBINED WITH CLINICAL ASSESSMENT IN THE EARLY DETECTION OF CRITICAL AND SEVERE CONGENITAL HEART DISEASE IN TERM NEONATES IN THE FIRST FOUR DAYS AFTER BIRTH}

\begin{abstract}
1,2,3PETROPOULOS ANDREAS*, Aynur Hudiyeva ${ }^{2},{ }^{2}$ Vali Behbudov, Gunel Mustafayeva 2 Aynur Babayeva ${ }^{4}$, Sevinc Mammadova ${ }^{5}$, Nader Guliyev ${ }^{6},{ }^{7}$ Ruslan Huseynov, ${ }^{8}$ Nabil Seyidov. 'Great Ormond Street Hospital, Baku, UK; ${ }^{2}$ Merkezi Klinika, Baku, Azerbaijan; ${ }^{3}$ The 'Aziz Aliyev' national postgraduate and CME medical training center, Baku, Azerbaijan; ${ }^{4}$ Baku clinic hospital,no 3, Baku, Azerbaijan; ${ }^{5}$ Republic Perinatal Center, Baku, Azerbaijan; ${ }^{6}$ Scientific Research Institute of Pediatrics, MoH of Azerbaijan, Baku, Azerbaijan; ${ }^{7} \mathrm{NICU}$ of Ob/G Institute of $\mathrm{MoH}$ of Azerbaijan, Baku, Azerbaijan; ${ }^{8} \mathrm{MoH}$ of Azerbaijan, Baku, Azerbaijan
\end{abstract}

\subsection{6/archdischild-2019-epa.402}

Background Since 2002 up to date, many studies around the world have proven the use of pulse oximetry(pox) as a screening test with high specificity, moderate sensitivity and a low overall false-positive rate, for detecting critical and severe Congenital Heart Diseases (c/s-CHD). It can be used as a preventive/early detective test for c/s-CHD, mostly in countries that luck high quality of medical services for CHD and/or have a high prevalence.
Aim Prospective study of screening by pox and compering pox + physical assessment, aiming to detect $\mathrm{c} / \mathrm{s}-\mathrm{CHD}$ in term neonates.

Population-Method From June 2016 to August 2018, 2570 term neonates were screened in two major maternity units in Baku-Azerbaijan. Pox levels using a motion-tolerant pulse oximeter where blindly reported on the end of the 1st and 3ed day of life by a team of trained nurses, using a simultaneous pre and post ductus arteriosus (pre/post DA) measurement. A second-team manded by neonatologists then assessed these neonates on the same dates. Firstly, blinded to existing pox measurements and then combining them together with Physical Assessment(pox+PA). Cut-offs of pathological pox were below $90 \%$ in any measured site or persisting pre/post DA difference $>3 \%$, following 2 assessments within 30 minutes apart. At day five from birth, all of them received Echo-2D screening from two examiners both double-blinded to the results of pox, pox + physician assessment and findings of primary Echo-2D.

Findings From 2570 screened neonates by Echo-2D, 47 CHD's were detected. From them, 17 were c-CHD and $5 \mathrm{~s}$ CHD. 25 were simple or moderate complex non-cyanotic CHD.

Regarding the pox team; detected $14 / 22$ (63.63\%) for c$\mathrm{CHD}$ at $24 \mathrm{~h}$ post-birth. This raised $18 / 22(81.81 \%)$ at $72 \mathrm{~h}$ post-birth. This team detected 65 cases $(2.2 \%)$ of additional neonatal non- cardiac pathology.

Combined team PA only 12/22(55.5\%) and 14/ (63.63\%). Pox +PA: $17 / 22(77.28 \%)$ and20/22(90.91\%) of $\mathrm{c} / \mathrm{s}-\mathrm{CHD}$ at 24 and $72 \mathrm{~h}$ post-birth respectable. Additional to that, 75 cases (3\%) neonatal non- cardiac pathology were detected.

Conclusion Pox $+\mathrm{PA}$ test when applied as late as $72 \mathrm{~h}$ post birth can serve as a screening/early detecting c/s-CHD test with a high positive predicted value. Additional can help countries with limited resourses in CHD surgery to improve their services and limit morbidity and mortality from $\mathrm{CHD}$ or other neonatal early presenting pathology.

\section{P48 STRUCTURAL-FUNCTIONAL CHANGES OF THE HEART IN DIFFERENT STAGES OF CHRONIC KIDNEY DISEASE IN CHILDREN}

Yulia Melnikova*, Tamara Makarova. Kazan State Medical University, Kazan, Russian Federation

\subsection{6/archdischild-2019-epa.403}

Chronic kidney disease (CKD) is a significant factor in the development of cardiovascular events.

Objective To study the structural-functional parameters of the heart in children at different stages of CKD according to echocardiography (EchoCG).

Material and Methods 104 patients with CKD were examined. The CKD stage was determined based on the estimated glomerular filtration rate. The first group consisted of 63 patients with CKD stage I, the second group included 26 patients with CKD stage III, and the third group of 15 patients with CKD stage V. Control group included 33 healthy children. All children performed echocardiography.

Results According to the results of the One-Way ANOVA test, the echocardiographic parameters differed significantly in the studied patients depending on the presence and stage of CKD ( $p<0,05$ for all parameters). In general, with the progression 